\title{
Use of a Class Exercise to Maximize Student Interest in an Introductory MIS Course
}

\author{
Arup Mukherjee \\ University of West Florida, Pensacola, FL, USA
}

\section{amukherj@uwf.edu}

\begin{abstract}
Students majoring in the College of Business at this University are required to take a course in information systems fundamentals as part of their business core. While it is easy for a faculty member to cover the necessary topics, it has been this instructor's experience that it is considerably difficult for students to see the importance and relevance of a study of information systems for success in a business career.

A class exercise has been developed and used successfully to provide students with a better understanding of the importance and relevance of a study of information systems. Students get a good understanding of the need for study of applications of information technology in improving business operations and solving business problems. The class exercise appears to be quite effective in helping students gain a higher level of interest in the study of information systems. Student evaluations suggest that the instructor was successful in stimulating a higher level of interest in the course.
\end{abstract}

Keywords: Class Exercise, Active learning, MIS relevance, student interest.

\section{Introduction}

Students majoring in the College of Business at this University are required to take a course in information systems fundamentals as part of their business core. In a typical course on information systems fundamentals, students are taught about computer hardware, software, data resource management, telecommunications, electronic commerce, e-business systems, decision support systems, developing information systems, and security and ethical challenges of such business systems. While it is generally easy for a faculty member to cover the necessary topics, it has been this instructor's experience that it is considerably difficult for students to see the importance and relevance of a study of information systems for success in a business career.

Why is a study of information systems important for a student majoring in a non-information systems major? Students of non - information systems majors such as Marketing, Finance, Accounting, Management, or Economics have a hard time understanding how a study of information systems will benefit their understanding

Material published as part of this journal, either on-line or in print, is copyrighted by Informing Science. Permission to make digital or paper copy of part or all of these works for personal or classroom use is granted without fee provided that the copies are not made or distributed for profit or commercial advantage AND that copies 1) bear this notice in full and 2) give the full citation on the first page. It is permissible to abstract these works so long as credit is given. To copy in all other cases or to republish or to post on a server or to redistribute to lists requires specific permission from the publisher at Publisher@InformingScience.org of businesses and help them in their business careers. Most of them come to the course with the perception that a study of information systems fundamentals may be relevant to Computer Science/ Computer Information Systems/ Management Information Systems majors but has little relevance to 
a good preparation for a business career. This negative perception makes it immensely difficult for the instructor to motivate the students to put in the effort needed to learn the material at a high level. A class exercise has been developed and used successfully to provide students with a better understanding of the importance and relevance of a study of information systems. Students get a good understanding of the applications of information technology in improving business operations and solving business problems. This, in turn, appears to provide the required impetus to make a serious study of business applications of information technology.

When a class exercise is used, students are engaged in a cognitive activity during part of a class period as opposed to being passive listeners for the entire class period. This strategy is known in the literature as 'active learning'.

Active learning has been widely used in academia and training for a long period of time. Learning becomes active when students use their minds during the learning process. More than two thousand years ago, Confucius suggested that people forget what they hear, but remember what they see and understand what they do. Active learning is thus learning through doing. In Silberman $(1995,1996)$, several strategies to incorporate active learning in courses and training sessions have been described. Wassermann (1994) confirms the widely held belief that opportunities to engage students actively in analyzing complex situations promotes their habits of logical thinking. Meyers and Jones (1993) believe that active learning helps students to become self-directed life long learners, an ability they will need many times in adjusting to the continuous changes that they are likely to encounter in their work places and society. Babbar (1994) describes the use of active learning in an Operations Management class. The students in this class perceived the activity to be relevant, valuable, and preferable to direct presentation of material in the traditional format. When a macro economics lecture was replaced with an active learning component, student grades in the relevant material was improved (Gremmen \& Potters, 1997). Ball (1999) describes successful use of an active learning exercise in a Negotiations class. She suggests that active learning is attractive for students because it is easier for students to focus their attention on something they are doing than on listening to a lecture.

First, I present a discussion about the nature of the course. This is followed by a discussion about the specific class exercise and how it was conducted. A discussion is presented about the diverse range of student responses. This is followed by details of the class discussion on the exercise. Finally, I summarize the benefits and drawbacks of this approach.

\section{Course Details}

A course in information systems fundamentals is required of all College of Business majors at this AACSB accredited regional university. The course suggests to students that information systems are both the backbone and the nervous systems of inter-networked e-business enterprises and that it is critical for a business student, regardless of the area of specialization, to learn to use and manage information technologies to improve business processes, conduct electronic commerce, improve business decisions, and gain advantage over competitors. This study of information systems is done through lecture presentations based on the text and other sources and case analyses. Another component of the course includes information analysis using relevant software packages. This typically includes analysis of data using spreadsheets and generation of reports using database management systems such as Microsoft Access. Students also learn to develop web pages for dissemination of their analysis and reports. The text used in the course is that by O'Brien (2003). The department updates to the latest edition of the text as and when it becomes available.

All College of Business majors are required to take the class. This includes such majors as Management, Management Information Systems, Accounting, Finance, Economics, and Marketing. 
Most students are in their junior years. Around $45 \%$ of students were females while $55 \%$ were males.

\section{Class Exercise}

The class exercise has two distinct stages. In the first stage, students answer five questions about critical issues pertaining to the use of automated teller machines (ATM). This particular common information technology application was selected for the exercise because college students usually have a degree of familiarity with ATMs. The class exercise is presented in Appendix 1. The questions involve identifying the most important advantage, the most important disadvantage, procedure to deal with a mistake made by the machine, security precautions, and changes that they would like to implement. Students are asked to write their answers down on the exercise sheet. The questions require them to think about the issue and express their own views. They are not permitted to discuss with others for this stage. This stage usually takes around 20 minutes.

The second stage is the discussion stage. Discussions are valuable because they are a form of active learning in which students must exert themselves to discover answers, listen well, and express their own thoughts (Prichard and Sawyer, 1994). At this stage the instructor discusses each of the five questions. For each question, a list of unique student responses are made on the board and discussed. This is followed by a quick tally of how many students had a specific unique response. This is done by asking for a show of hands for each unique response. When the class is closely divided on a specific question, the instructor may call for a discussion of reasons why students felt the way they did. Each student gets an opportunity to provide input on one or more of the five questions. The instructor decides the order in which students get to provide input. Thus all students are able to provide input. This process ensures that the discussion stage does not get dominated by a few strong students. This stage takes about 25 minutes. The total class time needed to complete the exercise was about 45 minutes. The class exercise is graded. Students are not permitted to make up missed class work.

\section{Student Responses}

A total of 27 students in one section of the course completed this class exercise in the Spring semester, 2003. An analysis of student responses is presented here in order to investigate the different dimensions of information technology use that were brought out by student responses. All the five questions are open-ended questions and student responses varied widely. In order to better understand the responses, they were grouped into general categories.

The first question asked the students about the most important advantage of a bank ATM. Appendix 2 shows a summary of the responses. Students felt that ATMs were convenient in terms of 24 hour, 7 days accessibility, were more efficient, saved customers from standing in long lines or getting out of their cars during bad weather, and provided better accessibility because of their availability near frequented places such as grocery stores.

The second question asked students to identify the most important disadvantage of ATMs. Appendix 3 shows a summary of responses. There were more unique responses about disadvantages than about advantages. Students identified lack of human help to resolve problems, higher cost due to ATM fees, lack of security due to lighting, limits on withdrawals from accounts, and inability to conduct all kinds of banking transactions as the most important disadvantages. Others considered the ease of account access with stolen card/ stolen information, inflexibility in identifying customers in alternate ways, lowered opportunities to build customer relationships, lack of security due to location in less congested areas, and the potential for customers to over spend be- 
cause of ease of access to their money as the most important disadvantages. It is clear from the student responses that they have strong feelings about the bank ATMs.

The third question asked the students to describe the procedure they would follow if the ATM machine made the mistake of dispensing $\$ 40.00$ when they made a withdrawal of $\$ 60.00$ from their bank account. Appendix 4 shows a summary of responses. The steps to be taken to respond to this scenario would include informing the bank as soon as possible and holding up the cash for the camera to see. Another student suggested making a balance inquiry to check what amount has been withdrawn and take corrective action only if the wrong amount has been withdrawn. Another response suggested that details about the incident such as date/ time and location of the ATM be noted immediately for report to the bank at the earliest convenience. Student responses suggested that they would not be terribly upset if this incident were to happen to them. They would proceed with an ad hoc procedure to try to get their $\$ 20.00$ back.

The fourth question asked about special precautions they would advise others to take when using an ATM machine. A summary of responses is shown in Appendix 5. This question brought out the largest number of unique responses. Further, the responses were very detailed indicating student concern about this issue. Student responses suggested being careful so that no one sees the PIN, keeping ATM card in a safe place, keeping receipts, watching out for attackers if it is dark, and withdrawing large amounts only during the day. Some others suggested not sharing PIN with any one, using ATMs that have lot of traffic, memorizing the PIN, not using ATMs for large withdrawals or large deposits, entering the PIN in a manner so that others can't see it, and counting the money while sitting inside their car with locked doors.

The fifth and final question asked students to identify improvements they would like to make to the ATM. Specifically the question asked them to identify one aspect of the typical ATM that they would like to change and why. Appendix 6 shows a summary of responses. The frequently reported desired change was about the ATM fee. Students were perturbed about the double fees charged when using an ATM outside their original bank network and wanted this to be eliminated. Other ideas about improvements included putting in a buzzer to get human attention in case of an error, locating ATMs at places so that security is not a concern even at night, implementing procedures that would require multiple means of identification, and implementing biometric means of user identification such as fingerprinting. Other students suggested putting ATMs in a lockable room that may be used by only one user at a time, increasing the limits on withdrawals permitted at the ATMs, putting account balance information on welcome page, and making instructions user friendly. To prevent user mistakes, one student suggested aligning the buttons better with the options available. Another student wanted more frequent preventative maintenance so that ATM outages will be reduced.

\section{Discussion}

The main goal of this exercise was to help students become more interested in the study of this introductory MIS course. Students had not been told about this goal.

Before use of the exercise, my first concern was whether the chosen scenario about ATM machines and the five specific questions will be of sufficient interest to the students to motivate them to take the class exercise seriously. The questions were open ended questions and students also had to state reasons for their answers. The diversity of the responses confirms that students come from a wide variety of backgrounds and perceive technology in different ways. For example, on the question about security precautions to be taken before use of the ATM, there were 15 unique answers from a group of 27 students. I had not expected students to exert themselves to the extent that they did and this came as a big surprise to me. 
Some of the answers were quite unexpected and suggest that students used their imagination and experiences in creative ways. The in depth nature of the answers suggests that the exercise succeeded in motivating the students to take the class work quite seriously. For example, there were 12 unique responses about changes that would improve the ATM experience. The issues identified were wide ranging and included security of location, user friendliness, preventive maintenance, error prevention strategies, strategies to improve efficiency, and strategies to prevent unauthorized access. All this would suggest that the exercise was successful in helping students be concerned about diverse issues pertaining to information systems. This careful consideration of a range of information systems issues suggests that the exercise succeeded in building a bridge between the students and the world of information technology.

Most students in this course (over $85 \%$ on an average each semester) are not information systems majors. They are there because it is a required course in the College of Business core. They are typically not interested in the subject matter. The instructor's main purpose in using this class exercise was to motivate this highly skeptical group to study the course seriously. In the next few paragraphs, I have described how the class work and subsequent discussion contributed towards getting the students more interested in this course.

Driscoll (2000) suggests that simply finding ways to actively engage students in learning can be an effective means of motivating them. The class exercise gave the students an opportunity to be cognitively active in determining several important dimensions of ATMs. Thus a higher level of motivation is expected to result.

Brookfield (1990) points out that the single greatest cause of resistance to learning is possibly fear of the unknown. Information systems are generally considered to be mysterious and complex objects by most business students. In answering questions about the ATMs, students discovered that information systems are ubiquitous and part of their daily activities. They discovered that they already know quite a bit about these systems because they interact with such systems on a regular basis. The exercise made information systems to appear less formidable and less distant and helped in lowering resistance to the material.

Driscoll (2000) suggests that students feel motivated to study what they consider to be relevant. The first two questions address the issue of relevance of information systems to a business career. The first question dealt with advantages of the ATM. Student answers pointed to such advantages for the customer as convenience, time savings, better accessibility, and quicker transactions. Students were quick to realize the power of information systems in bringing these important advantages to customers. When customers are happy, they reward the business by staying loyal to it. A direct advantage to the banks identified by the students was cost savings achieved by replacing tellers. Thus the answers to the first question identified significant benefits to the banks by use of the ATMs. It became apparent to students that information systems are a great tool to solve business problems and improve business operations. Answers to this question provided students with a good feel for the power of information systems in helping businesses achieve its goals. This realization made the subject matter relevant to them.

The second question dealt with disadvantages of the ATM. Student answers pointed to dissatisfaction with ATM fees, lack of human help if there is a problem, lack of security due to poor lighting, limits on transactions, and lower opportunities for building customer relationships. The students were quick to realize that use of information technology is not a panacea. It typically gives rise to greater efficiency in business transactions. However, it also takes away a lot in terms of lower human contact. Thus, while use of information technology solves some business problems, it also gives rise to others that need to be addressed in order for businesses to have better and stronger relationships with their customers. This discussion enables students to develop a balanced view about use of information technology in solving business problems. They realize that 
information systems are not a perfect solution to all problems. It has its weaknesses that future business leaders need to be aware of so that strategies may be devised to address these weaknesses. Again, this understanding of disadvantages of information systems made the subject more relevant because these weaknesses have the potential to affect businesses negatively.

Erickson (1984) suggests that students learn what they care about. The third question involves students in resolving a situation they care about and thus develop their interest. Specifically, the question asked students to identify steps they would take if the ATM made a mistake of dispensing \$20.00 lower than requested. From the perspective of a customer, this scenario is a big inconvenience because there is no easy or immediate solution to their problem. This question challenges students to think creatively about how to respond if this were to happen to them. The answers suggest that students were concerned about this possibility and cared about being able to resolve this problem.

Driscoll (2000) suggests that building student confidence makes them motivated for study of the material. The fourth question helps to boost student confidence. Specifically, the question asked students to identify security precautions to be taken when using the ATM machines. There were 15 unique responses to this question. Clearly students felt a high degree of interest in coming up with ideas for others to have a secured experience with the ATMs. This question gave the students an opportunity to give advice to others. In other words they got a feeling of importance because they were being treated as an expert. This helped to boost their confidence.

The fifth question boosts student confidence. Specifically the question asked students to identify one change they would like to make to the ATMs. Twelve unique suggestions were made in response to this question. Students were clearly excited about the opportunity to propose changes to an existing technology. This was also an opportunity for them to use their creativity which gave them satisfaction. Their opinions about improvements were being solicited through this question. This made them feel them important and boosted their confidence.

Another strategy to get students interested was by quickly connecting to each of them early in the semester. Prichard and Sawyer (1994) refers to this as 'immediate inclusion'. The discussion stage made this possible. In this stage the process used was to generate a list of unique answers on the black board (one question at a time). Each student had the opportunity to provide input about one or more questions. Thus, students heard their own voice early on in the term and hopefully felt safe about participating in discussions later in the course.

Driscoll (2000) suggests that building student confidence makes them motivated for study of the material. She indicates that students gain confidence in their own abilities when they actually experience success at challenging tasks. The class exercise is a unique experience for the students. They independently answer five questions about ATMs. They receive no help from the text, the instructor, or other students in answering the questions. They do the exercise without any advance notice or preparation. Completion of the exercise is in itself an achievement. However, when the answers to these questions are discussed they find that their answers are quite good compared to other students. Further, because the exercise is evaluated largely on seriousness of effort (there is no right or wrong answer), most students make full points on the exercise. All this adds up to a feeling of success. Hopefully this leads to more confidence in their own abilities and the consequent higher motivation. Further, this feeling of success in a challenging assignment, is also likely to help overcome resistance to learning (Brookfield, 1990).

\section{Benefits}

The exercise helped students gain greater interest in a study of information systems in several ways. Students were given an opportunity to understand the importance of use of information 
technology to solve business problems. The exercise made information systems appear less formidable and less distant and helped lower resistance to the subject matter. Answers to the five questions helped them appreciate the relevance of study of information systems to success in a business career. Many of the questions asked students for suggestions, which boosted their selfconfidence. The class discussion followed a strategy of immediate inclusion so that they would feel safe in participating in future discussions. Students also experienced success at a challenging task, which boosted their confidence and lowered resistance to the subject matter. They also had to write out the answers in their own language and this helped them practice their communication skills. During the discussion stage students had to present their answers in front of the class which gave them an opportunity to overcome their fears about talking in front of a peer group.

\section{Drawbacks}

Some of the drawbacks noticed are discussed in this section. The class exercise and follow up discussion took up around 45 minutes of class time. For this class session, this meant that very little content from the text could be covered. However, the importance of a more motivated group probably outweighs the disadvantage of less content as students achieved a better understanding of the relevance of the subject matter to business success. Another important drawback was that the exercise and its subsequent discussion had to be carefully planned by the instructor. However, the benefits of the class exercise clearly outweighed the drawbacks.

\section{Indirect Evidence of Effectiveness}

The university uses an 18 point instrument to collect student evaluations of instruction. Students are asked to rate the instructor on a 5 point Likert scale ranging from 'poor' to 'excellent'. For the purposes of our analysis the 'excellent' was treated as a ' 5 ' while a 'poor' was treated as a ' 1 '. This instructor usually teaches this course once a year in the Spring semesters. The most recent semesters when the instructor taught the course were Spring 2002 and Spring 2003. In Spring 2003 seven class exercises were used one of which is the class exercise described in this article. The other class exercises had different goals and will be described in future articles.

The main goal of the class exercise described in this article was to increase student interest in the course. One question on the evaluation form asked students to evaluate the instructor's success in stimulating interest in the course. In Spring 2002 (when this class exercise was not used), student responses to this question had a mean of $3.55(\mathrm{~N}=22)$. However, in Spring 2003 (when this class exercise was used), student responses to this question had a mean of $4.30(\mathrm{~N}=20)$. This difference is statistically significant $(\mathrm{t}=-2.225$; Sig. 2 tailed $=0.032$; equal variance not assumed $)$.

\section{Conclusion}

Students majoring in the College of Business at this University are required to take a course in information systems fundamentals as part of their business core. Unfortunately, it has been this instructor's experience that it is considerably difficult for students to see the importance and relevance of a study of information systems for success in a business career.

A class exercise was developed and used to provide students with a better understanding of the importance and relevance of a study of information systems. Students got a good understanding of how information systems help in improving business operations. Students feel motivated to study what they consider to be relevant (Driscoll, 2000). The exercise helped students see information systems as an integral part of business operations. This helped them see the relevance of such systems for business careers. Ericksen (1984) suggests that students learn what they care 
about. By asking them to devise a recovery strategy when a mistake is made by the ATM, the exercise got students involved and engaged in finding a way to recover from a situation that they truly care for and are worried about. Another question helped build student confidence by asking them to identify security precautions to be taken when using the ATM. Thus students got the feeling that their business acumen could be used to contribute to meaningful discussions pertaining to information systems. Again this confidence makes students more motivated to study the subject matter (Driscoll, 2000).

Instructors of business core courses always have a challenge in front of them. Each semester they encounter a group of skeptical students who major in other areas of business. If student interest is not stimulated at the beginning of the class, it is very difficult for an instructor to motivate students to do the strenuous work that is needed to acquire reasonable competence in the subject matter. Students who lack the motivation are unlikely to get enough understanding of the material to actually use it in practice. This instructor has been reasonably successful in using this and other class exercises to create greater interest in the subject matter.

\section{References}

Babbar, S. (1994). Molding students into better decision makers and managers: An experiential learning exercise. Journal of Education for Business, 69 (3), 149-153.

Ball, S.B. (1999). Pareto optimality in negotiation: A classroom exercise for achieving active learning. Journal of Education for Business, 74 (6), 341-346.

Brookfield, S.D. (1990). The skillful teacher. San-Francisco, California: Jossey-Bass.

Driscoll, M. P. (2000). Psychology of learning for instruction. Boston, Massachusetts: Allyn and Bacon.

Erickson, S.C. (1984). The essence of good teaching. San-Francisco, California: Jossey-Bass.

Gremmen, H. \& Potters, J. (1997). Assessing the efficacy of gaming in economic education. Journal of Economic Education, 28 (4), 291-303.

Meyers, C. \& Jones, T.B. (1993). Promoting active learning: Strategies for the college classroom. SanFrancisco, California: Jossey-Bass.

O'Brien, J.A. (2003). Introduction to information systems: Essentials for the e-Business enterprise. Boston, Massachusetts: McGraw-Hill-Irwin.

Prichard, K. W. \& Sawyer, R.M. (Eds.). (1994). Handbook of college teaching: Theory and applications. West Port, Connecticut: Greenwood Press.

Silberman, M. (1995). 101 ways to make training active. San Diego, California: Pfeiffer \& Co.

Silberman, M. (1996). Active learning: 101 strategies to teach any subject. Boston, Massachusetts: Allyn and Bacon.

Wassermann, S. (1994). Introduction to case method teaching: A guide to the galaxy. New York, NY: Teachers College Press.

\section{Appendix 1 \\ Class Exercise on Critical Issues in Use of Technology}

In this class work you will explore various aspects of the bank A.T.M. (automated teller machine) and try to understand critical issues in using technology. Recall that the A.T.M. was once used successfully by banks to create competitive advantage.

(Max points $=5$; each question is worth one point). 
1. What, in your opinion, is the most important advantage of a bank A.T.M. and why?

2. What, in your opinion, is the most important disadvantage of a bank A.T.M. and why?

3. What would you do if you withdrew $\$ 60.00$ from your checking account, but the machine dispensed $\$ 40.00$ and why?

4. What special security precaution would you advise a customer to take when using an A.T.M. and why?

5. If you could change one aspect of the typical A.T.M., what would it be and why?

\section{Appendix 2 \\ Summary of Student Responses to Question about Most Important Advantage of ATMs.}

1. Convenient because one can get to their money when they need it.

2. Saves user time because ATM transactions are quicker than human transactions.

3. Saves user from getting out of car if there is bad weather.

4. Makes banking possible for those who don't get off work before banks close.

5. Customer does not have to wait in long lines.

6. Better accessibility because ATMs are sometimes located near frequented places such as grocery stores/ gas stations etc.

7. Saves bank money by replacing tellers.

\section{Appendix 3 \\ Summary of Student Responses to Question about Most Important Disadvantage of ATMs}

1. No human available to help with problems.

2. Higher cost because ATMs sometimes charges fees for transactions.

3. Lack of security due to poor lighting.

4. Limits on how much money can be withdrawn.

5. Inability to conduct all kinds of banking transactions.

6. Lower security because thieves could get to account with stolen information/stolen card.

7. Inflexibility in identifying customers; e.g. if customer forgets PIN, can't use ATM.

8. Lowered customer relationship opportunities because of lowered face to face contact.

9. Lack of security due to location in unsecured places.

10. Some may spend more than they need to because it is too easy to get to the money; 


\section{Appendix 4 \\ Summary of Responses about Mistake Made by ATM in Dispensing Requested Cash}

1. Report it to bank when it reopens next.

2. Go inside bank right away and make them aware of problem.

3. Call and report the problem immediately to the bank so that cash balance can be checked.

4. Hold up the cash for the camera to see so that there is proof of the mistake.

5. Make a balance inquiry on account to verify that account is not overdrawn.

6. Keep transaction ticket to ensure that only $\$ 40.00$ was deducted from account.

7. Check receipt to see what was deducted from account; if $\$ 60$, call bank.

8. Inform the bank that ATM is not working properly.

9. Record date, time of incident, location of ATM and inform bank.

\section{Appendix 5 \\ Summary of Responses about Security Precautions to be Taken When Using an ATM}

1. Make sure no one is around to see your PIN.

2. Keep ATM card in a safe place.

3. Keep receipts for documentation in case technology fails in future.

4. If it is dark, watch out for attackers.

5. If large amounts are to be withdrawn, do so during the day.

6. Do not share your PIN number with any one.

7. Try to use ATMs that have lot of traffic.

8. Never write down your PIN number any where; memorize it.

9. Make sure you are in a well lit area.

10. Keep independent documentation of your transactions so that you don't bounce checks.

11. Do not use the ATM for withdrawing or depositing large amounts of cash due to the possibility of errors.

12. Always take the printed receipt with you; otherwise information about you may fall into wrong hands.

13. Enter PIN number in a manner so that others can't see it.

14. Count your money while sitting in your vehicle with locked doors.

15. Try to use ATMs that permit you to do the transaction without leaving your car. 


\section{Appendix 6 \\ Summary of Responses about Changing One Aspect of the ATM}

1. Remove ATM fee because it is not fair to charge a fee for withdrawing one's own money; implement a common ATM card and network so that no fees will apply.

2. Implement a buzzer to get attention from someone if there is a problem.

3. Locate ATMs at places so that security is not a concern even at night.

4. Implement a more comprehensive method for identifying the customer using multiple means of identification; this will make it difficult for a card thief to get access to the account because other required identification information is not available.

5. Use biometric identification such as fingerprinting instead of a card.

6. Eliminate use of card by use of passwords only to identify user.

7. Put the ATM in a lockable room that may be used by only one user at a time.

8. Increase the limits on amounts of withdrawals at the ATM.

9. Once user has been identified, let the first screen have balance information on checking account; saves time for most users who need this information to transact.

10. Make it easier and quicker for users by implementing user friendly instructions.

11. Reduce ATM outages by more frequent preventative maintenance.

12. Align the buttons better with the options so that user does not make mistakes.

\section{Biography}

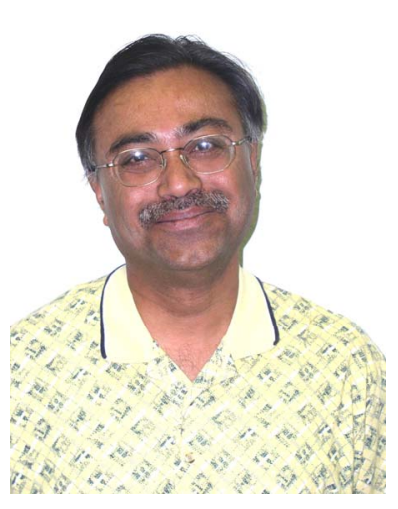

Arup Mukherjee received his B.Tech. degree in Electrical Engineering from the Indian Institute of Technology at Kanpur (India) and the Ph.D. in Management Science from the University of Tennessee (Knoxville, Tennessee, U.S.A.). He serves as a consulting editor for the Journal of Education for Business and on the Editorial Advisory Board for the Journal of Information Systems Education. His research has been published in such journals as Decision Support Systems and the Journal of the Operational Research Society. Ten of his major teaching innovations have been published in such journals as the Journal of Computer Information Systems, the Journal of Education for Business, Academy of Information and Management Sciences Journal and the Journal of Information Systems Education. He is currently Professor and Chair of the Department of Management/ Management Information Systems at the University of West Florida. 